\section{ESTÁGIO CURRICULAR SUPERVISIONADO NA FORMAÇÃO DE PROFESSORES DE EDUCAÇÃO FÍSICA NO BRASIL: UMA REVISÃO SISTEMÁTICA}

\author{
SUPERVISED PRACTICUM IN TRAINING OF PHYSICAL EDUCATION \\ TEACHERS IN BRAZIL: A SYSTEMATIC REVIEW
}

\author{
PRÁCTICA CURRICULAR SUPERVISADA EN LA FORMACIÓN DE \\ PROFESORES DE EDUCACIÓN FÍSICA EN BRASIL: UNA REVISIÓN \\ SISTEMÁTICA
}

Arestides Pereira da Silva Júnior ${ }^{*}$, Amauri Aparecido Bássoli de Oliveira**
Palavras chave:

Revisão.

Estágios.

Educação Física.

Atividades científicas e tecnológicas.
Resumo: O objetivo desta pesquisa do tipo revisão sistemática foi analisar a produção do conhecimento sobre o Estágio Curricular Supervisionado na formação de professores de Educação Física. Constatou-se que: há predomínio das publicações em periódicos B1 e B2 (48,7\%); a produção na área é recente, com maior quantidade de publicações entre 20112015 (76,9\%); os artigos classificados como de Intervenção foram os mais publicados $(51,3 \%)$; a temática Formação foi a que teve maior incidência (48,7\%); quanto ao tipo de pesquisa, os Estudos de Caso foram predominantes (41\%); as análises Qualitativas são amplamente mais utilizadas (89,8\%); Entrevistas $(25,6 \%)$ e Questionários $(23,1 \%)$ foram os Instrumentos mais empregados. Conclui-se que houve aumento na produção do conhecimento sobre essa temática nos últimos anos, contudo, ressalta-se a importância do fortalecimento das produções, objetivando acesso a periódicos mais bem classificados no sistema de avaliação.

Keywords:

Review.

Practicum.

Physical Education.

Scientific and technological activities.

Palabras clave: Revisión.

Prácticas.

Educación Física.

Actividades

científicas y tecnológicas.

\begin{abstract}
This systematic review looks into knowledge production about supervised curricular practicum in training of Physical Education teachers. Publications in B1 and B2 journals (48.7\%) prevailed. Production in the area is recent and most works were published between 2011 and 2015 (76.9\%). Articles categorized as 'intervention' were published most often (51.3\%). 'Education' was the topic with highest occurrence $(48.7 \%)$. Case studies prevailed (41\%) among research types and qualitative analyses were adopted much more often than others (89.8\%). Interviews (25.6\%) and questionnaires $(23.1 \%)$ were the most often applied instruments. Production of knowledge about the topic in recent years has increased, but it should be strengthened to access better classified journals in the evaluation system.
\end{abstract}

Resumen: Esta revisión sistemática analizó la producción del conocimiento sobre la Práctica Curricular Supervisada en la formación de profesores de Educación Física. Se constató que: predominan las publicaciones en periódicos B1 y B2 (48,7\%); la producción en el área es reciente, con mayor cantidad de publicaciones entre 2011 y 2015 (76,9\%); los artículos clasificados como de Intervención fueron los más publicados $(51,3 \%)$; el tema Formación fue el que tuvo mayor incidencia $(48,7 \%)$; en cuanto al tipo de investigación, los Estudios de Caso fueron predominantes (41\%); Ios análisis Cualitativos son ampliamente más utilizados $(89,8 \%)$; Entrevistas $(25,6 \%)$ y Cuestionarios $(23,1 \%)$ fueron los Instrumentos más empleados. Se concluye que hubo aumento en la producción del conocimiento sobre esa temática en los últimos años, sin embargo, se resalta la importancia de fortalecer las producciones con el objetivo de acceder a periódicos mejor clasificados en el sistema de evaluación.
*Universidade Estadual do Oeste do Paraná (UNIOESTE). Marechal Rondon, PR, Brasil.

E-mail: arestidesjunior2000@yahoo. com.br

**Universidade Estadual de Maringá (UEM). Maringá, PR, Brasil. E-mail: amauribassoli@gmail.com

Recebido em: 16-08-2016 Aprovado em: 01-11-2017

$\mathrm{DOl}:$ http://dx.doi.org/10.22456/1982-8918.67071 (c) (1) (3) Licence 


\section{INTRODUÇÃOO}

Ao longo das últimas duas décadas, sobretudo a partir da Lei no 9.394/1996 - Lei de Diretrizes e Bases da Educação Nacional (LDBEN) observa-se que o Estágio Curricular Supervisionado (ECS) ganha reconhecimento e valorização no contexto educacional, seja no campo burocrático e legal (principalmente com o Parecer CNE/CP 09/2001 e as Resoluções CNE/CP 01 e 02/2002 e 02/2015), no campo pedagógico ${ }^{1}$ ou no campo acadêmico com a publicação de inúmeros livros e artigos científicos que abordam esse tema nos cursos de licenciatura (SILVA JÚNIOR et al., 2016).

$\mathrm{Na}$ formação de professores de Educação Física (EF), o ECS se constitui como um espaço de preparação para o exercício da docência na escola, o qual deve privilegiar a articulação entre teoria e prática, a compreensão da realidade escolar, a valorização da postura crítico-reflexiva e a articulação entre ensino, pesquisa e extensão, de forma que considere a especificidade da disciplina de EF e o seu contexto de atuação (BENITES et al., 2012; IZA; SOUZA NETO, 2015; KRUG et al., 2015; NEIRA, 2012).

As pesquisas que abordam o ECS na formação de professores de EF têm investigado diversos assuntos e temas relevantes que podem auxiliar tanto os estagiários quanto os professores orientadores (da Instituição de Ensino Superior - IES) e professores supervisores (da escola) no processo de formação, capacitação e atualização pedagógica. Em um breve levantamento de artigos publicados, realizado a priori, de forma não sistemática e com objetivo centrado em identificar os principais temas ligados ao ECS na formação de professores de EF, constataram-se investigações sobre o professor supervisor (BENITES et al., 2012; SILVEIRA; BATISTA; PEREIRA, 2014), o estagiário (FARIAS et al., 2008), a relação entre IES e escola (IZA; SOUZA NETO, 2015), a relação teoria e prática (ZOTOVICI et al., 2013), a prática pedagógica (MARTINY; GOMES-DA-SILVA, 2014), a avaliação (SANTOS; SOUZA; BARBOSA, 2013), os aspectos legais (MONTIEL; PEREIRA, 2011; SILVA JÚNIOR et al., 2016), relatos de experiência (MOLETTA et at., 2013; NEIRA; EHRENBERG, 2013), dentre outros.

Ainda que se tenha um número considerável de produções cientíicas direcionadas a investigar o ECS na formação de professores de EF, até o momento não se tem uma organização sistematizada e com detalhamento de tais pesquisas. Assim, questiona-se: o que vem sendo pesquisado e produzido no campo acadêmico e científico em relação ao ECS na formação de professores de EF? Quais são os temas mais evidenciados nas pesquisas publicadas em periódicos nacionais? Quais as contribuições dessas publicações para a área? Quais são os temas que ainda não foram pesquisados? No intuito de encontrar respostas para essa lacuna, optou-se por realizar uma pesquisa do tipo "revisão sistemática" (GOMES; CAMINHA, 2014) das publicações científicas nacionais direcionadas ao ECS na formação de professores de EF.

Matos et al. (2013) afirmam que na EF ainda é dada pouca ênfase e notoriedade às pesquisas que delineiam o panorama da produção cientíica na área. Nesse sentido, no cenário da EF Escolar, podem-se citar como exemplos as pesquisas de: Antunes et al. (2005), que apresentaram um retrato da pesquisa brasileira em EF Escolar; Betti, Ferraz e Dantas (2011), na qual se propuseram realizar o estado da arte da EF Escolar e suas direções futuras; Bracht et al. (2011), que investigaram a produção de conhecimento sobre EF Escolar dos

1 Compreendendo o ECS a partir do entendimento de Pimenta e Lima (2012) como um processo de produção/ressignificação de conhecimentos, considerando o campo de atuação e estabelecendo relações com as disciplinas, com o objetivo de integrar o processo de formação discente. 
principais periódicos no Brasil de 1980 a 2010; Neira (2012) analisou a produção científica sobre a docência na EF em dois periódicos brasileiros; Dias e Correia (2013) realizaram um mapeamento da produção acadêmico-científica em periódicos nacionais a respeito da EF no Ensino Médio; Maldonado; Silva e Miranda (2014) analisaram a produção do conhecimento sobre o cotidiano da EF Escolar; Wiggers et al. (2015) analisaram tendências da pesquisa na EF Escolar no Brasil por meio da análise de periódicos no período de 2006 a 2012.

Referente ao ECS na formação de professores de EF, as únicas pesquisas deste cunho encontradas foram: uma revisão sistemática realizada por Silveira; Batista e Pereira (2014), mas que foi direcionada de forma específica a cartografar a tipologia de estudos focados no professor supervisor no ECS; e a pesquisa de Maffei (2014), que investigou as principais temáticas dos estudos referentes à formação de professores de EF no período de 2005/2014, especialmente as produções que abordam o ECS e a Prática como Componente Curricular. No entanto, ambas as pesquisas são restritas a investigar aspectos específicos que englobam 0 ECS na formação dos professores de EF.

Considerando a importância das pesquisas de revisão sistemática, a quantidade e qualidade das pesquisas publicadas que abordam o tema ECS na formação de professores de EF no Brasil, a inexistência de pesquisas que mapearam e analisaram de forma abrangente a produção científica nesta temática, decidiu-se pela realização desta pesquisa elencando como objetivo central analisar nos periódicos nacionais a produção do conhecimento sobre o ECS na formação de professores de EF.

\section{DECISÕES METODOLÓGICAS}

A pesquisa caracteriza-se como revisão sistemática. Em suma, a revisão sistemática disponibiliza um resumo das evidências de determinado tema, por meio de busca rigorosa e metódica (que valorize a reprodutibilidade), com avaliação e análise crítica, bem como síntese das informações. Esse tipo de pesquisa é útil por agregar informações de um conjunto de pesquisas distintas de temas em comum, que podem apresentar resultados convergentes e/ou divergentes. Além disso, fornece visão ampliada do que vem sendo produzido no contexto científico de forma a identificar as fragilidades, omissões e lacunas existentes na produção científica, bem como conhecer o panorama de publicações e as perspectivas para pesquisas futuras (THOMAS; NELSON; SILVERMAN, 2012; GOMES; CAMINHA, 2014).

Como forma de valorizar a reprodutibilidade e qualidade, todo o processo de revisão dessa pesquisa foi realizado por dois pesquisadores independentes, utilizando-se de um projeto de pesquisa preestabelecido (GOMES; CAMINHA, 2014).

Como fontes de informação para a busca dos artigos, recorreram-se às seguintes bases de dados eletrônicas: "Lilacs", "Scielo", "Scopus", "Web of Science", "Scopus", "Doaj", "Iresie", "Redalyc", "Oasis" e "Portal de Periódicos CAPES/MEC". Na seleção dos artigos para a pesquisa foram utilizados os seguintes descritores (português/inglês/espanhol): "estágio", "estágio curricular", "estágio supervisionado", "estágio curricular supervisionado" e "estágio docente". Como o objetivo foi selecionar apenas artigos direcionados ao ECS na formação de professores de EF, os operadores "and", "or" e "nof" foram utilizados para combinar os descritores na área da EF. Após a exclusão dos artigos duplicados, os selecionados foram lidos na íntegra e selecionados conforme adoção de critérios de inclusão e exclusão estabelecidas pelos pesquisadores. 
Critérios de inclusão: pesquisas sobre o ECS na formação de professores de EF; pesquisas nacionais sobre essa temática; pesquisas publicadas no período de janeiro de 1996 a dezembro de 2015 - a escolha de tal período se deu por entender que a LDBEN de 1996 foi um marco para o contexto educacional com repercussão direta na estruturação do ECS, bem como por acreditar que as duas últimas décadas podem retratar um panorama ampliado das pesquisas dessa temática.

Critérios de exclusão: pesquisas direcionadas ao bacharelado; artigos de revisão de literatura, de opinião, resenhas, ponto de vista, carta ao editor e editorial.

Fazendo uso dos critérios inclusivos, foram listadas 60 produções científicas; no entanto, após a adoção dos critérios de exclusão, 21 foram descartadas. Dessa forma, foram selecionados 39 artigos. A coleta dos artigos ocorreu entre os meses de março a maio de 2016.

Os artigos foram classificados quanto à avaliação do periódico, período de publicação, categoria, temática, tipo de pesquisa, tipo de análise e instrumentos utilizados. Em relação à avaliação dos artigos, utilizou-se o Sistema Qualis do Portal Capes ${ }^{2}$ como critério estabelecido para classificação dos periódicos. Quanto ao período de publicação, os artigos foram agrupados em intervalos de cinco em cinco anos. Sobre a temática, as categorias foram criadas a posteriori a partir do conteúdo apresentado nos artigos e ajustadas conforme comumente são expostas em publicações similares, como as de Folle e Nascimento (2008), Betti, Ferraz e Dantas (2011), Dias e Correia (2013), Maldonado, Silva e Miranda (2014).

Em relação ao tipo de pesquisa, análise e instrumentos, utilizaram-se como padrão as classificações propostas por Gil (2010), com adequações oportunas e necessárias, considerando as características dos dados. Dessa forma, as categorias estabelecidas e utilizadas foram as seguintes: Tipo de pesquisa - estudo de caso, pesquisa de campo, pesquisa documental, pesquisa participante e pesquisa-ação; Análise - qualitativa, quantitativa e Qualiquanti; Instrumentos - entrevista, questionário, documentos, relato de experiência, observação e múltiplos instrumentos.

Para a análise das categorias das publicações foi utilizada a proposta de Bracht et al. (2011) e adaptadas ao ECS na formação de professores de EF, na qual são ordenadas da seguinte forma: Fundamentação; Intervenção e Diagnósticos/descrições.

- Na categoria Fundamentação foram enquadradas as pesquisas que buscaram de alguma forma se apropriar de fundamentos ou bases teóricas para fortalecer o teor das discussões a respeito do ECS na formação de professores de EF;

- Foram enquadrados na categoria Intervenção os artigos que englobaram questões direcionadas à ação pedagógica "prática" nas investigações do ECS. Os artigos que abordaram a temática Formação também foram classificados na categoria Intervenção;

- A categoria Diagnósticos/descrições refere-se às pesquisas que buscaram apresentar o cenário de temas específicos do ECS na formação de professores de EF, a partir de pesquisa empírica e/ou relato de experiência.

A distribuição e a classificação dos resultados da pesquisa são apresentadas por meio de quadro e tabelas a partir da análise estatística descritiva de frequência ( $f$ ) e percentual $(\%)$.

2 Coordenação de Aperfeiçoamento de Pessoal de Nível Superior. 


\section{RESULTADOS E DISCUSSÃO}

Das 39 produções científicas selecionadas nesta pesquisa, 23 foram publicadas em periódicos da EF e 16 em periódicos da Educação. As publicações selecionadas foram classificadas a partir da proposição estabelecida pelo Sistema Qualis (2014) do Portal Capes (https://qualis.capes.gov.br) e estão apresentadas de acordo com a frequência de publicação na Tabela 1. É importante ressaltar que de acordo com a Capes, a classificação dos periódicos é realizada anualmente pelas áreas de avaliação, sendo enquadrados em estratos indicativos de qualidade - A1, o mais elevado; A2; B1; B2; B3; B4; B5; C - com peso zero.

Tabela 1 - Distribuição dos artigos por classificação dos periódicos no WebQualis.

\begin{tabular}{lcc}
\hline Qualis & $\boldsymbol{f}$ & $(\%)$ \\
\hline A1 & 0 & 0 \\
A2 & 2 & 5,1 \\
B1 & 9 & 23,1 \\
B2 & 10 & 25,6 \\
B3 & 2 & 5,1 \\
B4 & 0 & 0 \\
B5 & 2 & 5,1 \\
Sem classificação no Qualis de EF & 14 & 35,9 \\
\hline
\end{tabular}

Fonte: os autores.

Nesta pesquisa, constatou-se que quase a metade $(48,7 \%)$ dos artigos selecionados é de periódicos classificados com extratos B1 (23,1\%) e B2 (25,6\%). No entanto, percebese que esses 19 artigos (B1 e B2) foram publicados em apenas cinco periódicos nacionais (Motriz, Revista da Educação Física/UEM, Pensar a Prática, Revista Brasileira de Ciência e Movimento e Motrivivência), demonstrando baixa diversidade de opções de revistas com "boa" classificação no Qualis para o encaminhamento dos manuscritos. Ressalta-se que todos esses artigos (B1 e B2) foram publicados em revistas específicas da EF.

O panorama apresentado e exposto não é específico apenas em relação à publicação de artigos relacionados ao ECS na formação de professores de EF. Essa realidade se estende a toda área sociocultural em EF, na qual são restritos os periódicos com boa classificação no Qualis. Por exemplo, existe apenas um periódico brasileiro da Área $21^{3}$ classificado em A2 e nenhum em A1. Silva et al. (2015) também alertam acerca da dificuldade de publicar pesquisas de determinadas temáticas/características em periódicos brasileiros mais bem avaliados.

Outro aspecto que desperta atenção é o de que 35,9\% dos artigos foram publicados em periódicos que não estão enquadrados na classificação do Qualis. Acredita-se que o fato de que mais de um terço das publicações desta pesquisa pertencer a periódicos não classificados na Área 21 do Qualis possa dar indícios da escassez de possibilidades de periódicos mais bem classificados para submissão e publicação da produção científica da área sociocultural em EF. Várias pesquisas discutem a forma e o sistema como é

3 De acordo com a Capes (2013), a Área 21 é representada pelos programas de pós-graduação de Educação Física, Fisioterapia, Fonoaudiologia e Terapia Ocupacional, abrangendo áreas diversificadas de atuação acadêmica e profissional, que abarcam desde as características e demarcações biológicas e médicas até as de ordem pedagógicas, sociais e humanas. 
analisada, comparada e classificada a produção do conhecimento nessa área e apontam críticas, sobretudo na agregação de diferentes áreas e subáreas de incompatibilidade de comparação (ALMEIDA; BRACHT; VAZ, 2012; CARVALHO; MANOEL, 2006; DAOLIO, 2007; MARCHLEWSKI; SILVA; SORIANO, 2011; VITOR-COSTA; SILVA; SORIANO, 2012). Por outro lado, tais resultados podem servir de alerta sobre a importância de se fortalecer grupos de pesquisas que estudam o ECS na área da EF.

Ressalta-se que os 16 artigos selecionados de periódicos com classificação inferior (B5) ou sem classificação na Área 21 são da área da Educação. A desvalorização de artigos publicados fora da área faz com que a procura pelos periódicos da EF seja maior, no entanto, ainda é limitada a quantidade de periódicos nacionais bem posicionados na Área 21. 0 fato de a EF transitar entre as áreas de Ciências Sociais e Aplicadas e Educação e Saúde provoca distinções de produções que, por vezes, não são consideradas em uma ou outra área com o seu devido valor equitativo.

Nesse sentido, levantam-se alguns questionamentos: Será que periódicos bem conceituados na Educação não poderiam também ter maior reconhecimento na classificação da Área 21? Até que ponto os periódicos da Educação são importantes meios de divulgação das pesquisas que tratam da formação de professores em EF? Em que medida a produção do conhecimento sobre o ECS na formação de professores de EF poderia ser mais efetiva com a valorização dos periódicos da Educação? Não se pretende nesta pesquisa responder substancialmente a tais perguntas, mas a consideração e reflexão sobre tais indagações poderá ser o ponto de partida a outros estudos e ao trajeto epistemológico da produção do conhecimento ligado ao ECS na formação de professores de EF.

Com os resultados apresentados e considerando o sistema de classificação do Qualis, reforça-se a necessidade iminente de aumentar a quantidade de periódicos direcionados para as práticas sociais na Área 21, bem como ampliar a valorização dos periódicos da Educação, no intuito de possibilitar que os artigos sejam mais bem classificados e pontuados. Por outro lado, não é adequado fazer uma análise rasa e unilateral justificando a classificação não satisfatória dos artigos publicados, culpando única e exclusivamente a insuficiência de periódicos e a configuração das produções em áreas distintas.

Por mais que a presente pesquisa não tenha adentrado no mérito da qualidade dos artigos publicados, a grande quantidade de artigos publicados em periódicos não classificados no Qualis sugere que é necessário investir e aprimorar a produção científica que aborda o ECS na formação de professores de EF no sentido de avançar na classificação estabelecida. Tal constatação vai ao encontro dos apontamentos e críticas apresentados nos estudos de Almeida, Bracht e Vaz (2012), Carvalho e Manoel (2006), Daolio (2007), Marchlewski, Silva e Soriano (2011) e Vitor-Costa, Silva e Soriano (2012).

A análise da distribuição da produção por período de publicação é apresentada na Tabela 2, englobando a distribuição dos artigos por período de cinco anos. É importante destacar que essa pesquisa não buscou artigos com publicação anterior à LDBEN (1996), em que esse tema era tratado como Prática de Ensino sob forma de Estágio Supervisionado (SILVA JÚNIOR et al., 2016). 
Tabela 2 - Distribuição dos artigos por período de publicação.

\begin{tabular}{lcc}
\hline Período & $\boldsymbol{f}$ & $(\%)$ \\
\hline $1996-2000$ & 1 & 2,6 \\
$2001-2005$ & 1 & 2,6 \\
$2006-2010$ & 7 & 17,9 \\
$2011-2015$ & 30 & 76,9 \\
\hline
\end{tabular}

Fonte: os autores.

É notório que a produção dos artigos sobre o ECS na formação de professores de EF é recente e vem crescendo consideravelmente, principalmente no período que compreende 2011 - 2015 (76,9\%). No entanto, é importante frisar que o aumento não é específico dessa temática, o mesmo se deve também em função do acentuado produtivismo acadêmico mais recente e o consequente aumento da periodicidade e da quantidade de artigos nos fascículos das revistas. Kuhlmann Jr. (2015) critica esse aumento acentuado na produção acadêmica, pois de acordo com o autor a pressão por publicar em quantidade pode gerar conhecimentos ingênuos, oportunistas e desvirtuados dos reais objetivos da pesquisa científica.

$\mathrm{Na}$ Tabela 3 são apresentados os valores correspondentes ao resultado da distribuição dos artigos por categoria, conforme proposta de Bracht et al. (2011).

Tabela 3 - Distribuição dos artigos por categoria.

\begin{tabular}{lcc}
\hline Categorias & $\boldsymbol{f}$ & (\%) \\
\hline Fundamentação & 3 & 7,7 \\
Intervenção & 20 & 51,3 \\
Diagnósticos/descrições & 16 & 41 \\
\hline
\end{tabular}

Fonte: os autores.

Nos artigos pesquisados e analisados, observa-se a predominância de pesquisas classificadas como de Intervenção (51,3\%). É importante salientar que nessa categoria foram enquadrados também os artigos destinados a investigar o processo de formação de professores e isso fez com que o percentual fosse maior. Os artigos de Intervenção encontrados nesta pesquisa valorizam a pluralidade de práticas pedagógicas que abordam o ECS na formação de professores de EF e que se tornam importantes no sentido de evidenciar aspectos necessários para a formação (inicial ou continuada) do professor, bem como para o seu trabalho docente.

Dentre as várias subcategorias encontradas nos artigos do tipo Intervenção, destacamse aquelas que analisaram o estagiário no seu momento de formação, enfatizando suas experiências, as fragilidades e potencialidades do ECS (FARIAS et al., 2008; MOLETTA et al., 2013; KRUG et al., 2015; IZA; SOUZA NETO, 2015) e as investigações de temas recorrentes à prática pedagógica, como: inclusão, motivação, saberes docentes, métodos de ensino e avaliação (MARTINY; GOMES-DA-SILVA; 2011; FOLLE; TEIXEIRA, 2012; SANTOS; SOUZA; BARBOSA, 2013; MARTINY; GOMES-DA-SILVA; 2014).

Na pesquisa realizada por Bracht et al. (2011), que teve como objetivo principal realizar um mapeamento da produção do conhecimento sobre o tema EF Escolar nas últimas três décadas, os autores constataram que $34,8 \%$ dos artigos pesquisados foram classificados na 
categoria Intervenção. A pesquisa realizada por Wiggers et al. (2015), que objetivou identificar e analisar as principais tendências da pesquisa em EF Escolar, detectou o mesmo percentual $(34,8 \%)$ de artigos agrupados como Intervenção. Tais diferenças na comparação com os resultados deste artigo podem estar atreladas, principalmente, pela especificidade do tema ECS e sua relação próxima aos aspectos da prática pedagógica e à formação de professores.

Outros artigos, como os de Antunes et al. (2005), Betti, Ferraz e Dantas (2011), Dias e Correia (2013), também organizaram e distribuíram os artigos por categorias (finalidade, caracterização, processo ensino-aprendizagem, formação de professores, epistemologia, indefinido), bem como o de Maldonado, Silva e Miranda (2014), que definiram as categorias de acordo com a similaridade temática apresentada. No entanto, a categorização desses artigos foi diferenciada da desta pesquisa em virtude da natureza e característica da investigação, o que dificulta estabelecer comparações e inferências diretas.

De forma geral, considerando a quantidade de artigos encontrados (20) e enquadrados como de Intervenção, bem como a variedade dos seus desdobramentos, entende-se que atendem satisfatoriamente a abrangência de possibilidades de investigação e experimentação científica. No entanto, torna-se interessante o desenvolvimento de outras pesquisas no sentido de ampliar o leque de discussão e aprofundar as lacunas ainda existentes, como, por exemplo, pesquisas com maior tempo de intervenção e/ou com maior inserção com o contexto escolar, pois embora várias das pesquisas sejam classificadas como de Intervenção, ainda apresentam limitações quanto a esses aspectos.

Em relação à categoria Diagnósticos/descrições, esta apresenta sua relevância, sobretudo na exposição e valorização de experiências no contexto pedagógico formativo ligado ao ECS. Da totalidade de artigos encontrados, $41 \%$ foram classificados nessa categoria. A proporção de artigos do tipo Diagnósticos/descrições é similar à pesquisa de Wiggers et al. (2015), em que 39\% foram classificados nessa categoria e superior à pesquisa de Bracht et al. (2011), na qual $17,3 \%$ foram dispostos dessa forma.

Dentre esses artigos analisados da categoria Diagnósticos/descrições, destacam-se, na maioria das pesquisas, experiências centradas na identificação da importância e do papel do ECS na formação dos professores de EF (NUNES; FRAGA, 2006; FILGUEIRAS; RODRIGUES; VERENGUER, 2007; SILVA; SOUZA; CHECA, 2010; NEIRA; EHRENBERG, 2013). Mas também foram encontradas experiências do ECS em diferentes níveis e modalidades de ensino (AVANCE; SILVA; VENTORIM, 1999; QUARANTA; PIRES, 2013), no diagnóstico dos papéis e da função do professor supervisor (TELLES et al., 2015), bem como no desenvolvimento de conteúdos no estágio (FERNANDES; MARTINS, 2008).

Apesar de sua importância e necessidade no contexto educacional, as pesquisas do tipo Diagnósticos/descrições, em alguns casos, apresentam limitação pela fragilidade metodológica e fraca fundamentação teórica na análise empírica. Alguns textos se restringem à descrição de ações, situações, contextos e práticas pedagógicas sem a utilização de referências teóricas consistentes e que fundamentem a análise na compreensão de fenômenos sociais e na superação de discursos superficiais que ainda são recorrentes no sistema educacional, no qual a disciplina de EF está inserida.

Apenas três artigos (7,7\%) foram enquadrados na categoria Fundamentação, sendo a pesquisa de Zotovici et al. (2013), que teve como objetivo apresentar reflexões sobre o ECS no 
intuito de oferecer subsídios à práxis educacional como forma de subsidiar ações pedagógicas junto à EF. A pesquisa de Martiny e Gomes-da-Silva (2014), que objetivou (re)conhecer a reflexão como um dos elementos que sustenta a prática pedagógica dos professores em formação inicial durante o ECS, e a pesquisa de Silva (2003), que analisou a congruência entre uma proposta de formação profissional em EF às características de desempenho de estudantes em estágio.

As pesquisas de Antunes et al. (2005), Betti, Ferraz e Dantas (2011), Dias e Correia (2013) utilizaram a categoria Epistemologia para classificar investigações sobre a natureza do conhecimento do fenômeno estudado na área da EF, e tal categorização pode ser reconhecida como semelhante à categoria Fundamentação. Os resultados das pesquisas desses autores são similares ao desta investigação e indicam a carência de análises fundamentadas em bases epistemológicas consistentes que favoreçam o fortalecimento das práticas pedagógicas na EF. Nesse sentido, considerando os resultados obtidos, indica-se como fundamental que as produções científicas ligadas ao ECS na formação de professores de EF sejam pautadas na perspectiva de se aprofundar nas evidências do campo científico teórico, buscando soluções, explicações e confrontações que fortaleçam e valorizem o campo prático interventivo.

$\mathrm{Na}$ Tabela 4 é apresentada a distribuição dos artigos sobre o ECS na formação de professores de EF por temática específica.

Tabela 4 - Distribuição dos artigos por temática.

\begin{tabular}{lcc}
\hline Temática & $\boldsymbol{f}$ & $\mathbf{( \% )}$ \\
\hline Formação & 19 & 48,7 \\
Trato didático-pedagógico & 13 & 33,3 \\
Estrutura e organização do ECS & 3 & 7,7 \\
Modalidade de Ensino no ECS & 3 & 7,7 \\
Legislação & 1 & 2,6 \\
\hline
\end{tabular}

Fonte: os autores.

Constatou-se a predominância de artigos com temáticas direcionadas à Formação (48,7\%) e ao Trato didático-pedagógico (33,3\%). Tal evidência vai ao encontro dos resultados apresentados na distribuição por Categoria, tendo em vista a maior quantidade de artigos do tipo Intervenção, que, em sua maioria, englobam as pesquisas com temáticas relacionadas à Formação e ao Trato didático-pedagógico.

Considerando a especificidade das temáticas dos artigos que tratam o ECS na formação de professores de EF e a inexistência de pesquisas do tipo revisão sistemática e/ou estado da arte, não é coerente fazer comparações diretas ou até mesmo inferências indiretas com os resultados de outras pesquisas.

Não causa estranheza a elevada quantidade de artigos enquadrados como de Formação nesta pesquisa, sobretudo devido às necessidades emergentes e permanentes de se investigar temas relativos ao processo de formação e suas peculiaridades na EF, abrangendo a sua importância, dificuldades, percepções e interpretações, como destacaram as pesquisas de Nunes e Fraga (2006); Filgueiras, Rodrigues e Verenguer (2007); e Moletta et al. (2013). Nesta categoria também merecem destaque as iniciativas em investigar o papel e 
o perfil dos profissionais ligados diretamente ao processo de ensino e aprendizagem no ECS, como evidenciaram as pesquisas de Benites et al. (2012) e Telles et al. (2015).

Também foram encontradas pesquisas que analisaram a Estrutura e Organização do ECS (7,7\%), seja na IES ou na escola, bem como as relações e configurações entre as instituições envolvidas (SILVA, 2003; SILVA; SOUZA; CHECA, 2010; IZA; SOUZA NETO, 2015). Outra categoria em que os artigos foram classificados refere-se à Modalidade de Ensino no ECS (7,7\%), na qual foram encontrados artigos direcionados à Educação à Distância (QUARANTA; PIRES, 2013) e à Educação de Jovens e Adultos (AVANCE; SILVA; VENTORIM, 1999).

Um tema importante e ainda pouco explorado é referente à Legislação do ECS na formação de professores de EF, na qual foi encontrado apenas um artigo que explorou tal tema. A pesquisa de Montiel e Pereira (2011) procurou identificar os problemas evidenciados no desenvolvimento do ECS de 400 horas e verificar se os coordenadores de curso e professores orientadores de estágio consideraram positivas ou negativas as mudanças.

Nas Tabelas 5, 6 e 7 são apresentados os resultados referentes à caracterização e análise metodológica dos artigos selecionados nesta pesquisa.

Tabela 5 - Distribuição dos artigos por tipo de pesquisa.

\begin{tabular}{lcc}
\hline Tipo & $\boldsymbol{f}$ & (\%) \\
\hline Estudo de Caso & 16 & 41 \\
Pesquisa de Campo & 13 & 33,3 \\
Pesquisa Documental & 6 & 15,4 \\
Pesquisa participante e Pesquisa-ação & 4 & 10,3 \\
\hline
\end{tabular}

Fonte: os autores.

Quanto à caracterização do tipo de pesquisa, constatou-se que $41 \%$ dos artigos são Estudos de Caso. Os resultados apresentados para esse tipo de pesquisa são superiores aos dos estudos de Wiggers et al. (2015), com 17,8\%, e de Neira (2012), com 4,1\%. Ressalta-se que, embora as pesquisas tenham utilizado estudos de caso, as demais categorias não foram as mesmas dessa pesquisa, o que pode justificar tal discrepância.

Outro percentual elevado apresentado refere-se às Pesquisas de Campo $(33,3 \%)$, em que o resultado é similar ao de Wiggers et al. (2015), com 28,3\%. Também se evidenciou a Pesquisa Documental (15,4\%) como alternativa para pesquisa na área. Em menor proporção, foram encontrados apenas quatro artigos (10,3\%) do tipo Pesquisa-ação e/ou participante. Com o indicativo de tal resultado, sugere-se a realização de pesquisas com maior tempo de duração, de maior inserção do(s) pesquisador(es) no contexto da pesquisa e também que valorize mais de um único momento de coleta de dados (longitudinal).

Corroborando Alves (2009) e Neira (2012), verifica-se que ainda é notória a predominância de procedimentos investigativos convencionais, sendo tímidas as iniciativas com a utilização de métodos que transitam ou imergem em aprofundamentos metodológicos e teóricos das pesquisas, sobretudo as de cunho qualitativo que usualmente possibilitam investigação mais ampliada do fenômeno. Os autores ressaltam a necessidade de avançar e ousar nas abordagens qualitativas em EF, utilizando métodos na fenomenologia, hermenêutica, construtivismo social, crítico-dialética, dentre outros. 
Neste sentido, na Tabela 6 é apresentada a distribuição dos artigos pela forma de análise.

Tabela 6 - Distribuição dos artigos por análise.

\begin{tabular}{lcc}
\hline Análise & $\boldsymbol{f}$ & (\%) \\
\hline Qualitativa & 35 & 89,8 \\
Quantitativa & 2 & 5,1 \\
Quali-Quanti & 2 & 5,1 \\
\hline
\end{tabular}

Fonte: os autores.

De acordo com Goellner et al. (2010), as pesquisas com o viés qualitativo na EF, caracterizadas pela subjetividade e complexidade de fenômenos, seja das ciências humanas ou naturais, avançaram no sentido de possibilitar maior credibilidade por meio de rigor metodológico e métodos consistentes na análise e compreensão dos fatos. Neste sentido, constata-se nos resultados dessa pesquisa a predominância de artigos com abordagem Qualitativa (89,8\%). Ressalta-se que a análise foi feita a partir do que as próprias pesquisas se intitularam/ classificaram. 0 resultado se justifica, sobretudo, pela valorização de narrativas, relatos de experiências, estudos de caso e descrições de resultados de entrevistas ou questionários, nos quais a descrição e qualificação do fenômeno se sobressaem à quantificação do produto. Nesse sentido, o olhar calibrado e qualificado para a análise qualitativa exige do pesquisador expertise para tal.

Por outro lado, um percentual menor, representado por $5,1 \%$ dos artigos, foi caracterizado por pesquisas quantitativas. Do mesmo modo que $5,1 \%$ dos artigos estabeleceram análises que contemplam os dados tanto de forma qualitativa quanto quantitativa. Mesmo que no contexto educacional, no qual está inserido o ECS na formação de professores de $E F$, exista predominância das análises qualitativas nas pesquisas, frente aos resultados expostos, entende-se que trabalhar também com dados quantitativos possa contribuir para o aprimoramento da temática. Nessa direção, Dall-Farra e Lopes (2013, p. 67) afirmam que "a conjugação de elementos qualitativos e quantitativos possibilita ampliar a obtenção de resultados em abordagens investigativas, proporcionando ganhos relevantes para as pesquisas complexas realizadas no campo da Educação".

Ainda em relação à metodologia dos artigos, na Tabela 7 são apresentados os instrumentos utilizados.

Tabela 7 - Distribuição dos artigos por instrumentos utilizados.

\begin{tabular}{lcc}
\hline Instrumentos & $\boldsymbol{f}$ & (\%) \\
\hline Entrevista & 10 & 25,6 \\
Questionário & 9 & 23,1 \\
Documentos & 6 & 15,4 \\
Relato de experiência & 3 & 7,7 \\
Observação & 1 & 2,6 \\
Múltiplos instrumentos & 10 & 25,6 \\
\hline
\end{tabular}

Fonte: os autores. 
Usualmente o questionário e a entrevista são os dois tipos de instrumentos mais utilizados na pesquisa qualitativa. Considerando a predominância desse tipo de pesquisa nos artigos investigados, tal fato foi determinante na maior incidência desses instrumentos, representando $48,7 \%$ da totalidade na pesquisa. Outros instrumentos encontrados foram os documentos, os relatos de experiência, a observação, bem como a utilização de múltiplos instrumentos na mesma pesquisa.

Por fim, ressalta-se que os resultados desta pesquisa do tipo revisão sistemática sobre o panorama da produção do conhecimento científico do ECS na formação de professores de EF devem ser considerados em todos os aspectos analisados no sentido de evitar a repetição ou a realização de pesquisas desnecessárias em virtude do objeto já amplamente explorado e, sobretudo, no preenchimento das lacunas existentes. Além disso, a análise do estado da arte da produção do conhecimento possibilitará reconhecer as perspectivas, tendências e direcionamentos para pesquisas futuras.

\section{CONCLUSÃO}

A análise da produção do conhecimento sobre o ECS na formação de professores de EF no Brasil revela vários aspectos importantes no conhecimento da trajetória epistemológica desta área, no sentido de possibilitar o entendimento do cenário atual, bem como a identificação dos caminhos e sentidos a serem explorados no futuro. Com o desenvolvimento desta pesquisa do tipo revisão sistemática foi possível apresentar algumas considerações, ponderações e respostas aos questionamentos apresentados no texto, mas que não devem ser entendidas como ponto final, tendo em vista o panorama dinâmico da produção do conhecimento.

Constatou-se um avanço significativo na quantidade de artigos produzidos, pois até o ano de 2010 a produção científica direcionada ao ECS de forma específica para a EF era praticamente incipiente com um número bastante limitado de artigos. Embora o aumento quantitativo de artigos produzidos represente avanço considerável para a área, constatou-se que ainda são restritos os periódicos da EF com escopo voltado para as práticas sociais com "boa" classificação no Qualis Capes, o que restringe e acumula a publicação em um número reduzido de periódicos. Como forma alternativa para a publicação dos artigos, verificou-se a busca por periódicos da Educação, mas que, por sua vez, são pouco valorizados na Área 21.

Neste sentido, há a necessidade do fortalecimento dos periódicos direcionados para as práticas sociais, no intuito de possibilitar maior democratização e condições de "igualdade" na publicação desses artigos. De outro modo, também é condizente reconhecer a necessidade de solidificar e aprimorar os grupos de pesquisa dessa temática, bem como as produções científicas, em busca de publicações em periódicos mais bem classificados.

As temáticas mais evidenciadas e valorizadas nas pesquisas foram as referentes ao "Trato didático-pedagógico" e à "Formação". Por outro lado, ainda são quase inexistentes as investigações direcionadas aos aspectos de legislação, sendo uma lacuna a ser preenchida. Outro indicativo é da necessidade da realização de pesquisas que contemplem maior tempo de duração e de maior inserção do(s) pesquisador(es) no contexto de investigação, sugerindo pesquisas participantes e estudos longitudinais.

No que tange à classificação/categorização da produção, embora os artigos de intervenção e diagnóstico, que são predominantes, apresentem em sua maioria um respaldo 
teórico-metodológico, evidenciou-se a carência de pesquisas que enfatizem e valorizem os fundamentos e/ou bases teóricas. Desse modo, sugere-se que as pesquisas futuras explorem a partir do exercício da atividade epistemológica, e assim aprofundem seus métodos e a fundamentação teórica no sentido de valorizar e aproximar o campo teórico científico do campo prático interventivo.

Constatou-se que o aumento quantitativo e qualitativo das publicações dessa temática, no período analisado, vem apresentando contribuições importantes para a área, sobretudo no que diz respeito ao: aumento dos pesquisadores e grupos de pesquisas interessados em investigar essa temática; reconhecimento da importância dessa área na formação inicial dos professores de EF; necessidade da busca contínua de evidências científicas atuais na avaliação do ECS; e a tentativa (ainda que tímida) de aproximação do campo teórico/intelectual com o campo prático/intervenção.

Para finalizar, é importante destacar que, mesmo com a necessidade de progredir e avançar na produção do conhecimento sobre o ECS na formação de professores de EF, sobretudo nos indicativos apresentados nesta pesquisa, é considerável reconhecer o progresso da produção de artigos em periódicos nacionais nos últimos anos, sua relevância e contribuição para a área.

\section{REFERÊNCIAS}

ALMEIDA, Felipe Quintão; BRACHT, Valter; VAZ, Alexandre. Classificações epistemológicas na Educação Física: redescrições... Movimento, v.18, n.4, p.241-263, out/dez. 2012.

ALVES, Flávio Soares. Pesquisa qualitativa: desbravando territórios possíveis de se fazer ciência. Motriz, v.15. n.4, p.955-963, 2009.

ANTUNES, Fabia Helena Chiorboli et al. Um retrato da pesquisa brasileira em educação física escolar: 1999 - 2003. Motriz, v.11, n.3, p.179-184, 2005.

AVANCE, Alessandro; SILVA, Alex Aziel da; VENTORIM, Silvana. Estágio Supervisionado em Educação Física: uma experiência com educação de jovens e adultos. Motrivivência, v.11, n.13, p.1-13, 1999.

BENITES, Larissa Cerignoni et al. Qual o papel do professor colaborador no contexto do estágio curricular supervisionado na educação física? Revista Brasileira de Ciência e Movimento, v.20, n.4, p.13-25, 2012.

BETTI, Mauro; FERRAZ, Osvaldo Luiz; DANTAS, Luiz Eduardo Pinto Basto Tourinho. Educação física escolar: estado da arte e direções futuras. Revista Brasileira de Educação Física e Esporte, v.25, n. especial, p.105-115, 2011.

BRACHT, Valter et al. A Educação Física Escolar como tema da produção do conhecimento nos periódicos da área no Brasil (1980-2010): parte I. Movimento, v.17, n.2, p.11-34, abr./jun. 2011.

BRASIL. Ministério da Educação. Conselho Nacional de Educação. Parecer CNE/CP 09/2001. Diretrizes Curriculares Nacionais para a Formação de Professores da Educação Básica, em nível 
superior, curso de licenciatura, de graduação plena. Diário Oficial da União, Brasília, DF, 2001. Disponível em: <http://portal.mec.gov.br/cne/arquivos/pdf/009.pdf>. Acesso em: 15 jun. 2016.

BRASIL. Lei n. 9.394/96, de 20 de dezembro de 1996. Estabelece as diretrizes e bases da educação nacional. Diário Oficial da União, Brasília, DF, 23 dez. 1996. Disponível em: <http:// www.planalto.gov.br/ccivil 03/leis/L9394.htm>. Acesso em: 15 jun. 2016.

BRASIL. Ministério da Educação. Resolução CNE/CP 01, de 18 de fevereiro de 2002. Diário Oficial da União, Brasília, 2002. Disponível em: <http://portal.mec.gov.br/cne/arquivos/pdf/rcp01_02. pdf>. Acesso em: 15 jun. 2016.

BRASIL. Ministério da Educação. Resolução CNE/CP 02, de 19 de fevereiro de 2002. Diário Oficial da União, Brasília, 2002. Disponível em: <http://portal.mec.gov.br/cne/arquivos/pdf/CP022002. pdf>. Acesso em: 15 jun. 2016.

BRASIL. Ministério da Educação. Resolução CNE/CP 02, de 01 de julho de 2015. Diário Oficial da União, Brasília, 2015. Disponível em: <http://portal.mec.gov.br/index.php?option=com docman\&view=download\&alias=17625-parecer-cne-cp-2-2015-aprovado-9-junho-2015\&category slug=junho-2015-pdf\&ltemid=30192>. Acesso em: 15 jun. 2016.

CARVALHO, Yara M.; MANOEL, Edison de Jesus. Para além dos indicadores de avaliação da produção intelectual na grande área da saúde. Movimento, v.12, n.3, p.193-255, 2006.

COORDENAÇÃO DE APERFEIÇOAMENTO DE PESSOAL DE NÍVEL SUPERIOR. Documento da Área 2013. Disponível em: <https://www.capes.gov.br/images/stories/download/avaliacaotrienal/ Docs de area/Educa\%C3\%A7\%C3\%A30 F\%C3\%ADsica doc area e comiss $\%$ C3\%A30 att08deoutubro.pdf>. Acesso em: 20 jun. 2017.

DAL-FARRA, Rossano André; LOPES, Paulo Tadeu Campos. Métodos mistos de pesquisa em educação: pressupostos teóricos. Nuances: estudos sobre Educação, v.24, n.3, p.67-80, 2013.

DAOLIO, Jocimar. O ser e o tempo da pesquisa sociocultural em Educação Física. Revista Brasileira de Ciências do Esporte, v.29, n.1, p.49-60, 2007.

DIAS, Diogo Inacio; CORREIA, Walter Roberto. A Educação Física no ensino médio como objeto de estudo da produção acadêmico-cientifica dos periódicos nacionais. Revista Brasileira de Educação Física e Esporte, v.27, n.2, p.277-287, 2013.

FARIAS, Gelcemar Oliveira et al. Preocupações pedagógicas de estudantes-estagiários na formação inicial em educação física. Motriz, v.14 n.3, p.310-319, 2008.

FERNANDES, Carolina Noronha; MARTINS, Giorgia Enae. Circo da Escola: uma experiência de Estágio Supervisionado em Educação Física no $1^{\circ}$ Ano do Ensino Fundamental. Motrivivência, v.20, n.31, p. 187-191, dez. 2008.

FILGUEIRAS, Isabel Porto; RODRIGUES, Luiz Henrique; VERENGUER, Rita de Cássia Garcia. O estágio curricular supervisionado no curso de Licenciatura em Educação Física da Universidade Presbiteriana Mackenzie. Revista Mackenzie de Educação Física e Esporte. v.6, n.2, p.139-146, 2007.

FOLLE, Alexandra, NASCIMENTO, Juarez Vieira. Estudos sobre desenvolvimento profissional: da escolha à ruptura da carreira docente. Revista da Educação Física/UEM, v.19, n.4, p. 605-618, 2008.

FOLLE, Alexandra; TEIXEIRA, Fabiano Augusto. Motivação de escolares das séries finais do ensino fundamental nas aulas de Educação Física. Revista da Educação Física/UEM, v.23, n.1, p. 37-44, 2012.

GIL, Antonio Carlos. Como elaborar projetos de pesquisa. 5. ed. São Paulo: Atlas, 2010. 
GOELLNER, Silvana Vilodre. Pesquisa qualitativa na educação física brasileira: marco teórico e modos de usar. Revista da Educação Física/UEM, v.21, n.3, p.381-410, 2010.

GOMES, Isabelle Sena; CAMINHA, Iraquitan Oliveira. Guia para estudos de revisão sistemática: uma opção metodológica para as ciências do movimento humano. Movimento, v.20, n.1, p.395411, 2014.

IZA, Dijnane Fernanda Vedovatto; SOUZA NETO, Samuel. Os desafios do estágio curricular supervisionado em Educação Física na parceria entre universidade e escola. Movimento, v.21, n.1, p.111-124, 2015.

KRUG, Hugo Norberto et al. Ser professor na escola: de aluno a professor no estágio curricular supervisionado na licenciatura em Educação Física. Linhas, v.16, n.30, p.248-269, 2015.

KUHLMANN JR., Moisés. Produtivismo acadêmico, publicação em periódicos e qualidade das pesquisas. Cadernos de Pesquisa, v.45, n.158, p.838-855, 2015.

MAFFEI, Willer Soares. Prática como Componente Curricular e estágio supervisionado na formação de professores de Educação Física. Motrivivência, v.26, n.43, p.229-244, 2014.

MALDONADO, Daniel Teixeira; SILVA, Sheila Aparecida Pereira dos Santos; MIRANDA, Maria Luiza de Jesus. Pesquisas sobre a Educação Física no cotidiano da escola: o estado da arte. Movimento, v.20, n.4, p.1373-1395, 2014.

MARCHLEWSKI, Camila; SILVA, Priscilla Maia; SORIANO, Jeane Barcelos. A influência do sistema de avaliação Qualis na produção de conhecimento científico: algumas reflexões sobre a Educação Física. Motriz, v.17, n.1, p.104-116, 2011.

MARTINY, Luis; GOMES-DA-SILVA, Pierre. A transposição didática na educação física escolar: a reflexão na prática pedagógica dos professores em formação inicial no estágio supervisionado. Revista da Educação Física/UEM, v.25, n.1, p. 81-94, 2014.

MARTINY, Luis; GOMES-DA-SILVA, Pierre. "O que eu transformaria? muita coisa!": Os saberes e os não saberes docentes presentes no estágio supervisionado em Educação Física. Revista da Educação Física/UEM, v.22, n.4, p.569-581, 2011.

MATOS, Juliana Cassani et al. A produção acadêmica sobre conteúdos de ensino na Educação Física Escolar. Movimento, v.19, n.2, p. 123-148, 2013.

MOLETTA, Andréia Fernanda et al. Momentos marcantes do estágio curricular supervisionado na formação de professores de educação física. Pensar a Prática, v.16, n.3, p.715-730, 2013.

MONTIEL, Fabiana; PEREIRA, Flávio Medeiros. Problemas evidenciados na operacionalização das 400 horas de estágio curricular supervisionado. Revista da Educação Física/UEM, v.22, n.3, p.421-432, 2011.

NEIRA, Marcos Garcia. Alternativas existem! Análise da produção científica em dois periódicos brasileiros sobre a docência na Educação Física. Movimento, v.18, n.1, p.241-257, 2012.

NEIRA, Marcos Garcia; EHRENBERG, Mônica Caldas. Análise da proposta de estágio na licenciatura em Educação Física da Universidade de São Paulo. Olh@res, v.1, n.1, p.325-348, maio 2013.

NUNES, Rute Viégas; FRAGA, Alex Branco. "Alinhamento astral": o estágio docente na formação do licenciado em educação física na ESEF/UFRGS. Pensar a Prática, v.9, n.2, p.297-311, 2006. 
PIMENTA, Selma Garrido; LIMA, Maria Socorro Lucena. Estágio e docência. 7. ed. São Paulo: Cortez, 2012.

QUARANTA, André Marsiglia; PIRES, Giovani De Lorenzi. Histórias de vida e experiências docentes no estágio supervisionado de licenciandos em Educação Física - modalidade EAD. Movimento, v.19, n.2, p.185-205, 2013.

SANTOS, Rafaela Gomes dos; SOUZA, Adriano Lopes; BARBOSA, Franck Nei Monteiro. Estágio supervisionado I: o desafio da avaliação nas aulas de educação física escolar. Pensar a Prática, v.16, n.2, p. 501-518, 2013.

SILVA, Sheila Aparecida Pereira dos Santos. Desenvolvimento do pensamento crítico criativo e os estágios curriculares na área de Educação Física. Revista Brasileira de Ciência e Movimento, v.11, n.3, p.37-44, 2003.

SILVA, Eduardo Vinícius Mota et al. Atletismo (ainda) não se aprende na escola? Revisitando artigos publicados em periódicos científicos da Educação Física nos últimos anos. Movimento, v.21, n.4, p.1111-1122, 2015.

SILVA, Sheila Aparecida Pereira dos Santos; SOUZA, César Augusto Fernandes de; CHECA, Felipe Marques. Situação do estágio supervisionado em IES privadas da grande São Paulo. Motriz, v.16, n.3, p.682-688, 2010.

SILVA JÚNIOR, Arestides Pereira da et al. Estágio curricular supervisionado na formação de professores em educação física: uma análise da legislação a partir da resolução CFE 03/1987. Pensar a Prática, v.19, n.1, p.1-14, 2016.

SILVEIRA, Gonçalo Carlos; BATISTA, Paula Maria; PEREIRA, Ana Luísa. O perfil do professor cooperante no contexto da supervisão de estágio profissional: um estudo de revisão sistemática da literatura. Revista da Educação Física/UEM, v.25, n.2, p.309-321, 2014.

TELLES, Cassiano et al. As contribuições do Estágio Curricular Supervisionado para a aprendizagem docente dos professores-colaboradores da educação básica na percepção de acadêmicos/estagiários de Educação Física. Revista Eletrônica Fafit, v.6, n.1, p.1-7, 2015.

THOMAS, Jerry R.; NELSON, Jack K.; SILVERMAN, Stephen J. Métodos de pesquisa em atividade física. 6. ed. Porto Alegre: Artmed, 2012.

VITOR-COSTA, Marcelo; SILVA, Priscila Maia da.; SORIANO, Jeane Barcelos. A avaliação da produtividade em pesquisa na Educação Física: reflexões sobre algumas limitações dos indicadores bibliométricos. Revista Brasileira de Educação Física e Esporte, v.26, n.4, p.581597, 2012.

WIGGERS, Ingrid Dittrich et al. Um "raio-x" da produção do conhecimento sobre Educação Física Escolar: análise de periódicos de 2006 a 2012. Movimento, v.21, n.3, p.831-845, 2015.

ZOTOVICI, Sandra Aparecida et al. Reflexões sobre o estágio supervisionado no curso de licenciatura em Educação Física: entre a teoria e a prática. Pensar a Prática, v.16, n.2, p. 568-582, 2013.

Apoio:

Fundação Araucária de Apoio ao Desenvolvimento Científico e Tecnológico do Estado do Paraná; Coordenação de Aperfeiçoamento de Pessoal de Nível Superior (Capes). 